\title{
Results of the First Adapted Design for Sustainability Project in a South Pacific Small Island Developing State: Fiji
}

\author{
Michael D. K. Lobendahn Wood ${ }^{1}$, Fabrice Mathieux ${ }^{2}$, Daniel Brissaud ${ }^{2}$, \\ Damien Evrard ${ }^{3}$ \\ ${ }^{1}$ School of Engineering \& Physics - Faculty of Science, Technology and Environment - The \\ University of the South Pacific - Private Mail Bag - Suva, Fiji Islands \\ Email:wood_m@usp.ac.fi ; Phone: +6793232337 \\ ${ }^{2}$ Laboratoire G-SCOP - Université of Grenoble, 46 avenue Félix Viallet, F-38031 Grenoble Cedex 1, France \\ Email: fabrice.mathieux@g-scop.inpg.fr \\ Email: Daniel.Brissaud@inpg.fr \\ ${ }^{3}$ Pacific Centre for Environment - Sustainable Development - The University of the South Pacific \\ Email: evrard.d@gmail.com
}

\begin{abstract}
South Pacific will, in this century, be heavily impacted by global temperature and sea level rises. Small island developing states do have a number of unique problems, namely, small scale economic development together with environmental sustainability. This paper presents the lessons learnt from the implementation of the first cleaner production and design initiative project conducted in a Pacific small island developing state(s) (SIDS) using the design for sustainability (D4S) methodology. The final product was analysed using the life cycle assessment (LCA) method. Implemented within a medium-sized enterprise operating in Fiji, the Cook Islands, and Samoa, the project focused on improving an existing product and its associated lifecycle to make it more environmentally friendly to manufacture, retail, and dispose of. The project outcomes revealed that D4S provides a suitable tool for a country like Fiji to pursue more intensively an eco-friendly manufacturing agenda. However, when combined with LCA, the qualitative nature of D4S shows that not all solutions produce the best overall result. Specifically, the "improved" design, whilst being less impactful on Fiji in terms of disposal, has a higher impact globally due to the production and manufacture of the new materials used. For this reason designers need to address the impact criteria and decide whether a domestic or international agenda is of greater concern within the SIDS context.
\end{abstract}

KEYWORDS: Design for Sustainability, Ecodesign, Small Island Developing States, Life Cycle Analysis, D4S.

\section{Introduction}

\footnotetext{
${ }^{1}$ Corresponding Author: E-mail: wood_m@usp.ac.fj (M.D.K.L. Wood), Fax: +679 3231538, Ph: +679 3232337

${ }^{3}$ Currently unaffiliated
} 


\section{Sustainability in Small Islands Developing States}

Sustainable Development requires that "special attention [is paid] to the developmental needs of Small Island Developing States and the Least Developed Countries" [1]. Indeed, SIDS in the Caribbean, the Indian Ocean and the Pacific are remote, in-development, rich with traditional knowledge and made up of unique and fragile ecosystems. Therefore, SIDS are especially vulnerable to current development trends, from economical, social and ecological perspectives [2]. Furthermore, achieving sustainable development while overcoming economical, social and environmental concerns is a pivotal challenge for governments of SIDS such as Fiji. Consequently, the 2007-2012 Fiji Government's Strategic Development Plan lists sustainable development, incorporating environmental sustainability, as a priority for national policy [3].

\section{Economical, social and environmental challenges of the Fiji Islands}

Consisting of 332 islands (110 inhabited) with a total land area 18,274 sq.km; Fiji is small compared to its much larger and more developed island neighbours, Australia and New Zealand. With a population of 944,720 Fiji has a GDP of USD $\$ 3790$ GDP/capita in 2008 [4] and a current account deficit equivalent to $23 \%$ of GDP; Fiji relies heavily on imports. The labour force of 335,000 are spread over 3 basic areas; agriculture (8.9\%), industry (13.5\%), and services (77.6\%) [4]. The major industries are tourism, sugar, and the clothing industry. There are numerous small- to mediumenterprises (SMEs) operating successfully in SIDS as well as some large enterprises. In the garment sector for example, many SMEs export their production for overseas consumption. Currently $52 \%$ of all Fijians live in urban settlements and this figure is growing at a rate of $1.6 \%$ annually. With this trend of Rural-to-Urban shift comes a number of problems.

Considering that Fiji's trade deficit in 2007 was FJD\$1.68billion, it faces the issue of reducing imports whilst finding alternative domestic producers to create social and economic opportunities. This is particularly important since SIDS are highly dependent on foreign imports, wholly or in part, to fuel economic activity.

In addition to these economical and social issues, environmental concerns bear heavily on Fiji's ability to sustain development. Municipal waste management systems are currently highly stressed and inefficient, waste treatment and effective disposal of industrial waste, fresh and ocean water security and degradation of highly sensitive and unique ecosystems in Fiji, adaptation to climate change are also a major concern [4].

\section{The solid waste issue in the Fiji Islands}

At the forefront of environmental concerns, solid waste management (SWM) was identified by the Department of Environment as being the single largest environmental problem facing Fiji [2]. Like most SIDS, Fiji has limited pockets of useable land for which to dispose of household and industrial waste with 7 out of the 11 current dump sites located in mangroves [2]. The waste problem is today 
increasing in Fiji, like in other SIDS, due to increasing urbanisation, increasing volume of waste, changes of composition of waste, linked to changing consumption patterns (waste contains today more post-consumer products and hazardous waste) and increasing costs of technology [5]. The solid waste issue is also accounted for in the environmental vulnerability index (EVI). Developed by the Pacific Islands Applied Geoscience Commission (SOPAC) and the United Nations Environment Programme (UNEP) in 2004 [6] and based on previous work [7], the EVI aims to identify those sources of vulnerability that can negatively influence the sustainable development of countries and thereby build resilience. In this regard, the vast majority of 'smart indicators' identified in the EVI are highly relevant to Fiji and other Pacific SIDS, with several related to human activity and the solid waste issue, these are: 17 - ecosystem imbalance, 27 - degradation, 38 - waste production, 39 - waste treatment [8]. For the majority of these indicators the priorities for reducing vulnerability, and thereby positively influencing sustainable development, is to minimise resource abuse, avoid damage to natural ecosystems particularly chemical and physical damage, increase recycling and minimise waste and waste importation, particularly toxic waste.

A project was initiated at the University of the South Pacific (USP) in 2003 with the aim of seeking adapted and sustainable solutions to solid waste problems in the Pacific. Since 2003, many tasks related to better solid waste management have been carried out, for example; the development of a green waste composting pilot [9] and an adapted powder-based recycling technology for aluminium [10]. Boosted through the identification by the Fiji Government of Life Cycle Thinking, as a possible solution to Fiji's SWM problems [11], the project presented in this paper aims to promote a more preventative approach, through cleaner design and production.

\section{Cleaner production and LCA in SIDS}

While end-of-pipe developments such as sanitary landfills or waste water treatment plants are increasingly available in SIDS, cleaner production initiatives are still in their infancy. Only one cleaner production experience in SIDS concerning a brewery and a tannery was retrieved in the literature: the analysis brings relevant site-specific improvement opportunities, such as recovery of $\mathrm{CO}_{2}$ and heat, and recirculation of co-products to produce additional beer [12]. Meanwhile, like in Africa, Life Cycle Assessment (LCA) is still a very new approach in SIDS: some university basedpractitioners are trying to set-up a network of practitioners, and to promote its use towards industry and policy-makers, but it is not widely used in the real life [13]. The first reported use of LCA in SIDS occurs in 2008 where it was applied in Mauritius on the end-of-life scenarios of PET bottles. Results were then used to help Government in decision-making [14].

\section{Ecodesign in developing countries}

Although ecodesign is very popular in Europe, Japan, Australia and the USA, it is still weakly addressed in developing economies. This is in particular the case for SIDS where no ecodesign 
experience was identified in the literature. Brazil, although considered an emerging economy is utilising ecodesign tools and methods to improve locally designed products [15], [16]. In 1999, a paper related a successful sustainable product development experience with SMEs in Mexico: a thorough training with a local community led to the development of new resource efficient wooden products [17]. Unfortunately, the absence of a precise step-by-step method adapted to the Mexican context hindered the replication of the experience. A thorough study published in 2003 explains this weakness for Central America by the facts that the environmental laws are unclear, usually outdated and mostly irrelevant for most of the industries [18]. It also shows that environmental awareness and performances of industries are very low, in particular for local SMEs and less for companies exporting to Europe and the USA. The need to switch from pure ecodesign to wider Sustainable Product Design, that also integrates social and ethical aspects, is also identified by the same author. It finally analyses numerous case studies of ecodesign in Central America where a so-called "unpackaged technology transfer", for which the recipient can learn and build up the necessary local capacity, and for which more of the local resources can be used, is applied to ecodesign.

To address the deficiencies in ecodesign adapted for developing countries; UNEP sponsored the development of a publication by the University of Technology Delft that provides a simple step-bystep methodology, called Design for Sustainability (D4S). This methodology focuses on the needs of

SMEs specifically in developing economies. D4S adopts a practical approach to sustainability by assessing the needs of these enterprises and providing the necessary tools to improve their products. Accessibility to the D4S toolset is very easy and freely available along with a detailed guide "Design for Sustainability - A practical Approach for developing economies" [19].

\section{Aim of the paper}

The purpose of this paper is to show that the D4S methodology is relevant for SIDS but that a complimentary quantitative assessment should be considered for the methodology to effectively enhance good design decisions. Although the initial stages of the application of D4S methodology on a backpack in Fiji was already presented [20] the paper fully documents the process of analysis and redesign, and suggests adaptations of the D4S methodology for Fiji. The following sections describe the methods involved and results obtained. Finally a discussion and the conclusions of the project are presented.

\section{Methods}

\subsection{The Design for Sustainability project launched by USP}

The D4S methodology has been launched in 2007 by UNEP for designing products taking into account economic, social, and ecological perspectives. In the same year, the first adapted D4S project in Fiji was administered by the University of the South Pacific's Pacific Centre for Environment and Sustainable Development under the direction and leadership of a young French "Chargé de mission", 
trained on European ecodesign issues, and researchers from University of Grenoble, France. In order to adapt this project to the local context it was essential to establish links and coordinate D4S activities with Pacific Islanders already on the ground; this ensured that the project was an inclusive process involving local stakeholders. The project took approximately 6 months to implement with the following objectives:

1. To introduce the D4S methodology to Fiji;

2. To observe its effectiveness and suitability within the SIDS context;

3. To propose adaptations to ensure the methodology produces the best results for SIDS.

Figure 1 provides a summary of how the D4S methodology was implemented and adapted in Fiji. After the initiation of the Project, including country benchmarking and identification of target sectors, the method was applied within a partner company, and in this case to an existing product, a school backpack (Backpack 1). The redesign of the backpack was then executed using the available D4S strategies to produce a redesigned product, "Backpack 2". The adapted methodology then evaluated Backpack 2 using LCA and a second iteration, Backpack 3, was produced. Finally Backpack 3 was approved for mass production and introduced into the market along with an informative label identifying the environmental changes to the product. The use of the LCA and the development of an informative label are modifications of the initial D4S methodology; the adapted D4S method.

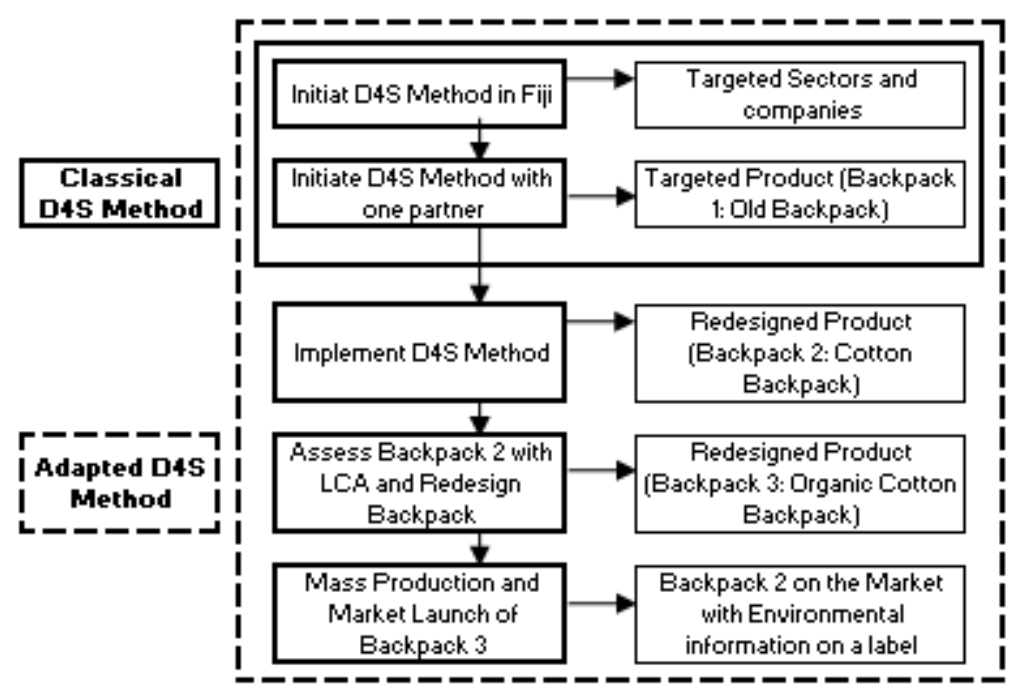

Figure 1 Adapted D4S Project implementation Strategy in Fiji

The first steps prior to selecting a sector to apply the methodology consists of collecting country benchmark statistics such as GDP figures, import and export levels as a percentage of GDP, identifying sectors of national importance, current developments, the characteristics of the local industry and how does the project support the majority of industries or those at the forefront of industrial development. This was relatively easy with the Fiji Islands Bureau of Statistics releasing statistics detailing the size and composition of the Fiji economy. Furthermore, the Fiji Islands Trade 
and Investments Bureau have released studies on the trends and developments in the Fijian economy. The D4S strategy also calls for the classification of sustainability issues into environmental (planet), social (people), and financial (profit) categories thereby allowing for the selection of a sector of significant importance to the national economy. Following this, all relevant sectors were analysed using a strengths, weaknesses, opportunities, and threats (SWOT) analysis and companies were approached with potential ideas for D4S projects. The 3 major manufacturing sectors within the Fiji economy from an ecodesign perspective were the footwear, garment, and furniture sectors [4].

Due to the need for regular meetings with the D4S team, the decision was made to limit the approach to an industrial partner/SMEs operating within the greater Suva urban area where a population of 172,000 people, or $21 \%$ of the total population, reside.

Whilst accessibility to the D4S methodology is easy, implementation was far more difficult. The second step was to search for a willing partner. The initial approach involved phone calls, emails, and direct visitations to prospective companies with accompanying leaflets presenting the project and its associated benefits. It was found that most companies were unwilling to take part.

The first interested party was then secured: Wai Tui Surf, a Fiji based textile and recreational goods manufacturing company with outlets in Fiji, Samoa and the Cook Islands. Wai Tui is 100\% Fijian owned with 55 employees in the textile manufacturing arm of the business. Wai Tui exports $40 \%$ of its products mainly to Australia and New Zealand. The primary reasons for engaging in this project were to increase exports, using a differentiated product, with the knowledge that external markets are now highly sensitive to environmental and sustainability issues.

An analysis of the significance of the textile industry in Fiji revealed that the textile industry represents 15,000 workers, with the majority of them women, the incomes of which support the lives of 80,000 people, $20 \%$ of all urban households [21]. This study further recognises the garment industry as a 'critical' sector for Fiji in terms of economic growth, foreign investment, employment creation and skills development. In 2008, the Fiji garment industry was worth FJD\$57,682 million, $1.18 \%$ of total GDP at current prices, down $3.2 \%$ on 2007 figures. Unfortunately, this is indicative of the trend experienced by the garment industry as it continues to contract amid an evolving global trade setting that no longer favours Fiji. One of the major criticisms levelled at the Fijian garment industry is that "the sector has struggled to mature in terms of becoming an efficient and economically sustainable industry" and its "inability to value-add to products and develop key markets outside of its own region" are severely impeding growth. Therefore, Fiji needs the garment industry, if only for employment; to be innovative, responsive to new markets and trends, efficient and sustainable.

\subsection{Implementing the adapted D4S Methodology within Wai Tui}

The adapted D4S design flow chart [22] modified from that proposed by UNEP is shown in Figure 2. 


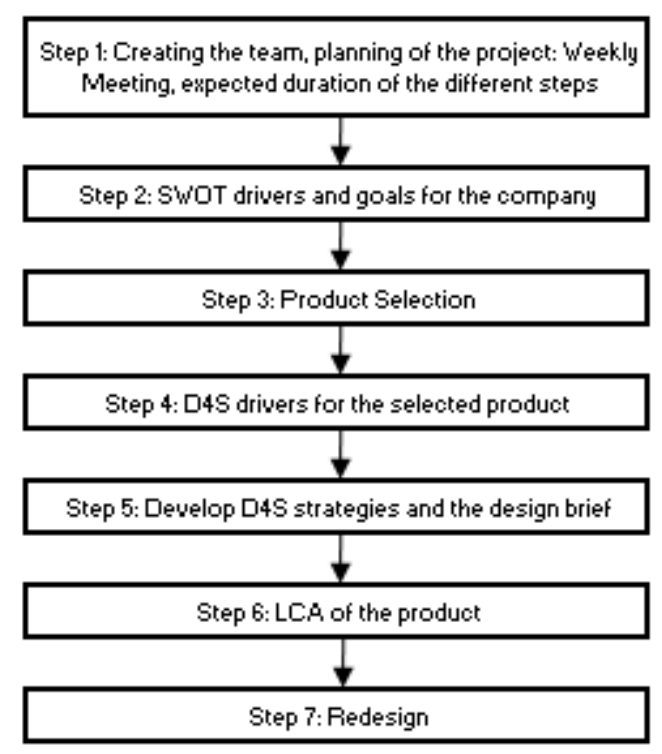

Figure 2 Adapted D4S Product redesign steps applied within this Project

\subsubsection{Step 1: Creating the Team, Planning the Project}

In order for the project to be inclusive rather than consultative, a team was formed within the company. The team met once a week for 1 hour and consisted of the General Manager and various product development team members: the production manager, printing process manager, quality manager, the garment department manager, graphical designer, the storage (inputs/outputs) manager, the sales and marketing manager, and finally the D4S consultant who oversees the entire process, in this case the French chargé de mission. By forming a design team from various sections, the aim is to have a fully integrated design that addresses the concerns of each of the departments and also to facilitate its appropriation by the company.

\subsubsection{Step 2: SWOT drivers and goals for the company}

A SWOT analysis of the company was then completed by the team. Including the well established weaknesses of developing countries SMEs (e.g. poor employee education levels, lower technology base etc), this study revealed results unique to SIDS, in particular the lack of a domestic primary industry supplying local manufacturers needs, geographical isolation and the cost and delays associated with import of raw materials (as weaknesses). As a unique strength, the South Pacific's pristine, sun filled, a relaxed image and its closeness to large consumers markets such as Australia and New Zealand.

Once the SWOT was complete it became clear to the team what the internal and external drivers would be for the company moving forward. The goals for the company were to concentrate on limiting costs whilst capitalising on the strengths outlined in the SWOT study. The main drivers for this project highlighted by the team were: the optimisation of the end-of-life (EoL) scenarios; the use of renewable materials, waste reduction, and bag aesthetics. 


\subsubsection{Step 3: Selecting the Product}

For the first application of the D4S methodology it was important to work on an existing product rather than design a completely new product. The selected product was: a school bag referred to hereafter as the 'Backpack 1'. Table 1 displays the materials used in the Backpack 1. Made primarily from polyester and screen printed using Plastisol PVC paint, the backpack has two storage compartments, one large, the other small, both having access via plastic zippers with metallic sliders. The backpack has two shoulder straps with $10 \mathrm{~cm}$ thick Polyurethane foam padding. The nylon webbing/straps are adjustable by means of two PVC ladderlocks. The bag is sewn using polyester thread.

Table 1 Backpack 1 material composition

\begin{tabular}{|c|c|c|c|c|c|c|c|}
\hline \multicolumn{8}{|c|}{ BACKРАСК 1} \\
\hline Item Description & Usage & Unit & Material & Total & Unit & Weight & Unit \\
\hline Polyester 600denier $-152 \mathrm{~cm}$ & 110 & $\mathrm{~cm}$ & Nylon & 16720 & $\mathrm{~cm}^{2}$ & 379.1 & $\mathrm{~g}$ \\
\hline \multicolumn{8}{|l|}{ Zip No.5 } \\
\hline zip teeth & 150 & $\mathrm{~cm}$ & PP & 150 & $\mathrm{~cm}$ & 22.9 & $\mathrm{~g}$ \\
\hline fabric & 150 & $\mathrm{~cm}$ & Nylon & 150 & $\mathrm{~cm}$ & 11.3 & $\mathrm{~g}$ \\
\hline Zip Slider No.5 & 4 & piece & Spelter & 4 & piece & 14.3 & $\mathrm{~g}$ \\
\hline \multicolumn{8}{|l|}{ Piping - 4mm Polyprop Cord } \\
\hline fabric & 270 & $\mathrm{~cm}$ & nylon & 270 & $\mathrm{~cm}$ & 17.7 & $\mathrm{~g}$ \\
\hline inside rubber & 270 & $\mathrm{~cm}$ & synthetic rubber & 270 & $\mathrm{~cm}$ & 15.7 & $\mathrm{~g}$ \\
\hline cord & 270 & $\mathrm{~cm}$ & nylon+cotton & 270 & $\mathrm{~cm}$ & 4.4 & $\mathrm{~g}$ \\
\hline Cellaire Foam - $126 \mathrm{~cm}$ & 10 & $\mathrm{~cm}$ & $\mathrm{PU}$ & 126 & $\mathrm{~cm}$ & 17.6 & $\mathrm{~g}$ \\
\hline Webbing $25 \mathrm{~mm}$ & 115 & $\mathrm{~cm}$ & nylon & 115 & $\mathrm{~cm}$ & 16.1 & $\mathrm{~g}$ \\
\hline Ladderlock $25 \mathrm{~mm}$ & 2 & piece & PVC & 2 & piece & 12.1 & $\mathrm{~g}$ \\
\hline Printing - Plastisol PVC & 40 & $\mathrm{ml}$ & & 40 & $\mathrm{ml}$ & & \\
\hline Thread - Polyester Bonded & 200 & metres & nylon & 200 & $\mathrm{~m}$ & 17.2 & $\mathrm{~g}$ \\
\hline
\end{tabular}

This product was relevant for the following reasons:

1. The school bag is a strong performer in terms of sales for the company

2. Highly useful for the Fijian population

3. All design for Backpack 1 is done in-house where as a number of their products are backward engineered and redesigned.

4. The product exhibits potential for immediate improvement due to its limited complexity.

\subsubsection{Step 4: D4S Drivers}

In addition to the redesign of the school bag it was decided that all related processes within the school bag production line would also be optimised. The D4S drivers for the resigned product were:

1. Planet Sphere: minimise materials used, their impacts, and improve the end-oflife waste treatment as well as production waste.

2. Profit Sphere: profit parity with current school bag and improve sales

3. People Sphere: redevelopment of a useful product for the local population; improved working conditions at the factory.

\subsubsection{Step 5: D4S Strategies for product improvement and Design Brief}


The D4S worksheets, available free online were integral in providing strategies for product improvement. From the creativity sessions that took place, four of the seven D4S improvement options were chosen by the team:

1. Select low impact materials

2. Reduce the use of materials

3. Optimisation of Production techniques

4. Optimisation of the end-of-life system

Once the backpack 1 was analysed, the team brainstormed to come up with a comprehensive design brief incorporating the four suggested D4S improvement options. After completing the D4S methodology as outlined in Figure 2, it was decided to assess the real impact of the new backpack (Backpack 2) with respect to the original backpack, Backpack 1.

\subsubsection{Step 6: LCA of the Product}

In 2008 the University of the South Pacific (USP) was awarded a one year single user commercial license to use SimaPro 7.1 and EcoInvent V2 database by the UNEP and Society of Environmental Toxicology and Chemistry (SETAC) through the Life Cycle Initiative. During this period a lifecycle inventory of the original and redesigned backpack was developed and a LCA was carried out with comparisons of the alternatives, following the ISO 14040 and 14044 guidelines [23, 24]. It should be noted that such an analysis is not necessary and is beyond the scope of the original D4S methodology since it requires costly software, extensive training and knowledge in the area, in addition to IT skills and infrastructure. Conducting LCA of products, building Life Cycle Inventories (LCIs) and Life Cycle Impact Assessment (LCIA) methods, is an extremely time consuming, and invasive activity requiring the collection of detailed material data, production information, conditions of use and disposal; information that most SIDS SMEs would otherwise disregard or not always record; and in most cases a LCA may be perceived purely as an academic activity and may discourage companies from adopting the D4S methodology if LCA is packaged with it. However, given that the industrial partner was willing to participate, it was important and significant that the first D4S project conducted in Fiji be quantitatively assessed against its perceived improvement choices and the project goals.

\section{Functional Unit}

In this study, the system is the backpack and the functional unit is "carrying a $10 \mathrm{~kg}$ load for 10 years within Fiji”. It is quite common for bags in Fiji to be used in this manner and for this duration. After use the bag is usually thrown away to a landfill or burnt with household waste.

\section{Boundaries and Data Quality}

The systems identified during this LCA are the same for backpack 1 and backpack 2 and are composed of six relevant life cycle stages displayed in Figure 3: 


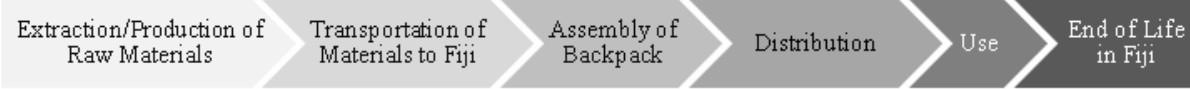

Figure 3 Backpack life cycle stages

The usage phase of the backpack was initially considered, but its environmental impact was eventually nil: although the washing of the bag has some environmental impact, it was not believed to be different for the two backpacks and was thus ignored in the study. It was however advised to use dark colours for the redesigned backpacks so that washing was an uncommon practice. The distribution phase of the backpacks was considered in as far as packaging but the production of capital goods/production equipment and transportation to retail stores was not. In this study, the environmental impact of capital goods manufacture was considered negligible compared to the operation load of the machines, tools, and buildings. The processes incorporated into this lifecycle includes all processes in, but not limited to, Fiji. $100 \%$ of all elements used in the fabrication of these backpacks are sourced entirely from overseas suppliers. With the exceptions previously discussed only raw material extraction/production and all steps up to the disposal scenario are considered here. The data collected for the LCA inventory was supplied by the company in various forms and categories. A complete inventory of materials/sub-assemblies used in the construction the backpacks including their respective weights, usage, shipping details from point of origin to Fiji including shipment packaging was tabulated. Data on the energy used for assembly was also collected at the Fiji textile company. Inventories contained in the EcoInvent database were used for the inventories of all other processes. However, the electricity production mix and the end-of-life scenario in Fiji needed to be created. Although this inventory is not completely accurate (most inventory data used are typical for Europe), this data was used since no other inventory was available.

\section{LCIA Methods and Determination of Relevant Impact Categories}

Inbuilt in SimaPro are a number of LCIA methods containing numerous impact categories used for determining the impact assessment of a product, assembly, or process. This posed a number of problems for this project since most of SimaPro's LCIA methods are interpreted and weighted according to location, in general Europe and the United States. It was therefore necessary to identify impact categories relevant to the Fiji context.

In order to avoid any LCIA normalization and weighting problems, as no such approach is available for Fiji, only mid-points methods were chosen. CML 2 baseline 2000 method was chosen for this reason and also because it is recognized worldwide.

The priority areas for sustainable development discussed in this paper and highlighted by the EVI Index suggest that not all the impact categories in the CML 2 Baseline 2000 V2.04 methods are as important in a SIDS context as they are in a region such as Europe. Moreover, CML method appears 
limited when considering some environmental impacts very relevant to the Fiji context, e.g. waste production and energy consumption. The final list of impact categories considered in this LCIA study are presented in Table 2: this table is a mixture of some CML 2 Baseline 2000 indicators as well as user defined simple inventory indicators such as hazardous waste, bulk waste, water and energy consumption. Hazardous and bulk waste were created essentially to quantify the amount of waste by identifying which materials and production stages in the backpack life cycle that create the most bulk waste and hazardous waste. Water and energy consumption in Fiji and in other countries is also included to identify the impact of the backpacks on global and local water and energy supplies.

Global impact categories such as global warming and abiotic depletion do not pose any geographical relevance in our case but are considered in the analysis considering that they are of global concern and that all raw materials are produced overseas. However, regional/local indicators such as human toxicity and marine aquatic ecotoxicity do pose geographic relevance problems as they can vary upon the local environment sensitivity. Fiji ecosystems are in this respect very different from European ecosystems and CML indicators are definitely not fully adapted to our study, especially for flows occurring in Fiji. However, since there are no other available LCIA methods adapted to the Fiji context, these indicators were considered.

Table 2 Impact Categories used in the LCA study

\begin{tabular}{|l|l|}
\hline \multicolumn{1}{|c|}{ CML 2 Baseline 2000 V2.04 } & \multicolumn{1}{c|}{ Indicators highly relevant to Fiji } \\
\hline \hline Abiotic depletion & Abiotic depletion \\
\hline Acidification & Eutrophication \\
\hline Eutrophication & Global warming (GWP100) \\
\hline Fresh water aquatic ecotoxicity & Human toxicity \\
\hline Global warming (GWP100) & Marine aquatic ecotoxicity \\
\hline Human toxicity & \\
\hline Marine aquatic ecotoxicity & Inventory indicators \\
\hline Ozone layer depletion & Hazardous waste \\
\hline Photochemical oxidation & Bulk waste \\
\hline Terrestrial ecotoxicity & Water Consumption \\
\hline & Energy Consumption \\
\hline
\end{tabular}

\section{Development of Fiji Energy Mix and Fiji End-of-life Scenario}

Extracted from the 2007 Fiji Electricity Authority annual report [25], Fiji's electricity mix was created in SimaPro for the purposes of analysing the assembly processes that occur on island. The energy mix comprises $64.8 \%$ hydroelectric, $32.5 \%$ diesel generation, $0.4 \%$ wind, and $2.3 \%$ biomass. Inventories of these energy sources provided by EcoInvent were used Table 3.

Prior to October 2005, the greater Suva area was serviced by municipal waste disposal facilities and a central dump site at Lami Town with volume reduction of waste by uncontrolled incineration. With the completion of the Naboro landfill in $2005,24 \mathrm{~km}$ west of Suva, approximately $25 \%$ of Fiji's population now has access to its first sanitary landfill constructed according to EU standards. The remainder of the waste is considered to be uncontrollably burnt at the rubbish dump site without any energy recovery or treatment of smoke and ashes. Presented in [26, 27] are results of incineration experiments on cotton and polyester fabrics under laboratory/control conditions, that provide 
composition of emissions to air, ground and water. The following data was used to create the inventory of a typical "Fiji uncontrolled burning" process (cf. Table 3).

Table 3. Summary of "Fiji energy mix" and "Fiji end-of-life scenario" processes created within SimaPro software.

\begin{tabular}{|c|c|c|}
\hline Processes created in SimaPro & Type (Source) & Share \\
\hline \hline \multirow{4}{*}{ Fiji Electricity Mix } & Hydroelectric (EcoInvent - Electricity, Hydropower, at power & $64.8 \%$ \\
& plant, CH) & \\
\cline { 2 - 3 } & $\begin{array}{c}\text { Diesel (EcoInvent - Electricity, Oil, At power plant, UCTE) } \\
\text { Fiji End-of-Life Scenario }\end{array}$ & $32.5 \%$ \\
\cline { 2 - 3 } & Biomass (EcoInvent - Electricity, Bagasse, Sugar cane, At & $2.3 \%$ \\
\cline { 2 - 3 } & Sugar refinery, BR) & $0.4 \%$ \\
\cline { 2 - 3 } & Wind (EcoInvent - Electricity, At wind power, RER) & $25.0 \%$ \\
\hline & Sanitary landfill (EcoInvent - Landfill, CH) & $75.0 \%$ \\
\hline
\end{tabular}

\subsubsection{Step 7: Redesign}

Based on the results of the LCA conducted on Backpacks 1 and 2, a second design iteration of the backpack was produced, backpack 3 , for which organic cotton was preferred to conventional cotton. LCA was applied to this new design and all results are now presented.

\subsection{Results}

The results presented here assume two forms: the first being that of the D4S methodology, the second relating to the Life Cycle Assessment conducted on all backpacks.

\subsection{Results of the D4S Methodology - Product Improvement}

The new school backpack derived through the application of the D4S methodology has a number of technical and environmental improvements. These are:

1. The polyester fabric was substituted for a cotton fabric with a waterproof and anti rot treatment; hereafter referred to as backpack 2. A second iteration of this backpack (hereafter referred to as backpack 3) directly followed, the main alteration being the use of organic cotton in place of the conventionally produced cotton fabric. The second modification should increase the life time of the backpack through the use of polypropylene zip sliders in place of the zinc alloy (spelter) which would otherwise rust in salty tropical climate, The major difference between the cotton and organic cotton fabric arises from the extensive use of fertilizers and pesticides in the growth of the cotton crop and higher productivity yields [28]. Both cotton fabrics originate from China and the US via a distributor based in Australia.

2. A water based paint was used in place of an acrylic based paint. The processes used for paint application and curing did not change for the substituted paint.

3. The quantity of plastic used to package the bags for distribution was reduced by $97 \%$ by wrapping 50 school bags in 1 large plastic bag rather than individually wrapping each bag. 
The inventory for Backpacks 2 and 3 are displayed in Table 4.

Table 4 Backpack 2 and 3 material breakdown

\begin{tabular}{|c|c|c|c|c|c|c|c|}
\hline \multicolumn{8}{|c|}{ ВАСКРАCK 2 \& 3} \\
\hline Item Description & Usage & Unit & Material & Total & Unit & Total & Unit \\
\hline Cotton Canvas* $-185 \mathrm{~cm}$ & 70 & $\mathrm{~cm}$ & cotton & 12950 & $\mathrm{~cm}^{2}$ & 356.0 & $\mathrm{~g}$ \\
\hline \multicolumn{8}{|l|}{ Zip No.5 } \\
\hline zip teeth & 150 & $\mathrm{~cm}$ & PP & 150 & $\mathrm{~cm}$ & 22.9 & $\mathrm{~g}$ \\
\hline fabric & 150 & $\mathrm{~cm}$ & Nylon & 150 & $\mathrm{~cm}$ & 11.3 & $\mathrm{~g}$ \\
\hline Zip Slider No.5** & 4 & piece & Spelter & 4 & piece & 14.3 & $\mathrm{~g}$ \\
\hline \multicolumn{8}{|l|}{ Piping - 4mm Polyprop Cord } \\
\hline fabric & 270 & $\mathrm{~cm}$ & nylon & 270 & $\overline{\mathrm{cm}}$ & 17.7 & $\mathrm{~g}$ \\
\hline inside rubber & 270 & $\mathrm{~cm}$ & synthetic rubber & 270 & $\mathrm{~cm}$ & 15.7 & $\mathrm{~g}$ \\
\hline cord & 270 & $\mathrm{~cm}$ & nylon+cotton & 270 & $\mathrm{~cm}$ & 4.4 & $\mathrm{~g}$ \\
\hline Binding 25mm Polyprop & 26 & $\mathrm{~cm}$ & nylon & 26 & $\mathrm{~cm}$ & 2.9 & $\mathrm{~g}$ \\
\hline Cellaire Foam - $126 \mathrm{~cm}$ & 10 & $\mathrm{~cm}$ & $\mathrm{PU}$ & 126 & $\mathrm{~cm}$ & 17.6 & $\mathrm{~g}$ \\
\hline Webbing $25 \mathrm{~mm}$ & 115 & $\mathrm{~cm}$ & nylon & 115 & $\mathrm{~cm}$ & 16.1 & $\mathrm{~g}$ \\
\hline Ladderlock $25 \mathrm{~mm}$ & 2 & piece & PVC & 2 & piece & 12.1 & $\mathrm{~g}$ \\
\hline Printing - Permaset Water Based & 20 & $\mathrm{ml}$ & & 20 & $\mathrm{ml}$ & & \\
\hline Thread - Polyester Bonded & 200 & metres & nylon & 200 & $\mathrm{~m}$ & 17.2 & $\mathrm{~g}$ \\
\hline Rubber tag & 1 & piece & synthetic rubber & 1 & piece & 2.7 & $\mathrm{~g}$ \\
\hline Velcro & 13 & $\mathrm{~cm}$ & nylon+PP & 13 & $\mathrm{~cm}$ & 2.3 & $\mathrm{~g}$ \\
\hline *Backpack 3 uses Organic Cottor & & & & & Total Mass & 513.0 & $\mathrm{~g}$ \\
\hline
\end{tabular}

** Backpack 3 uses PP sliders

The factory-centred impacts that were achieved during this D4S project were:

1. The electricity used by the air compressor at Wai Tui was reduced by $50 \%$ simply by implementing a switch-off procedure when idle.

2. Improved work safety of staff.

3. An increase of $30 \%$ in waste paper collection for recycling at the cutting room floor.

The backpack obviously benefited from these factory improvements: for example the electricity used for the assembly of the bag was considered reduced by $50 \%$. Of the factory-centred improvements, it is difficult to quantitatively assess improved worker safety; however perception/worker sentiment was overwhelmingly positive. 
3.2 LCA of D4S Improvement Opportunities

\subsubsection{LCA comparison of the 3 alternatives}

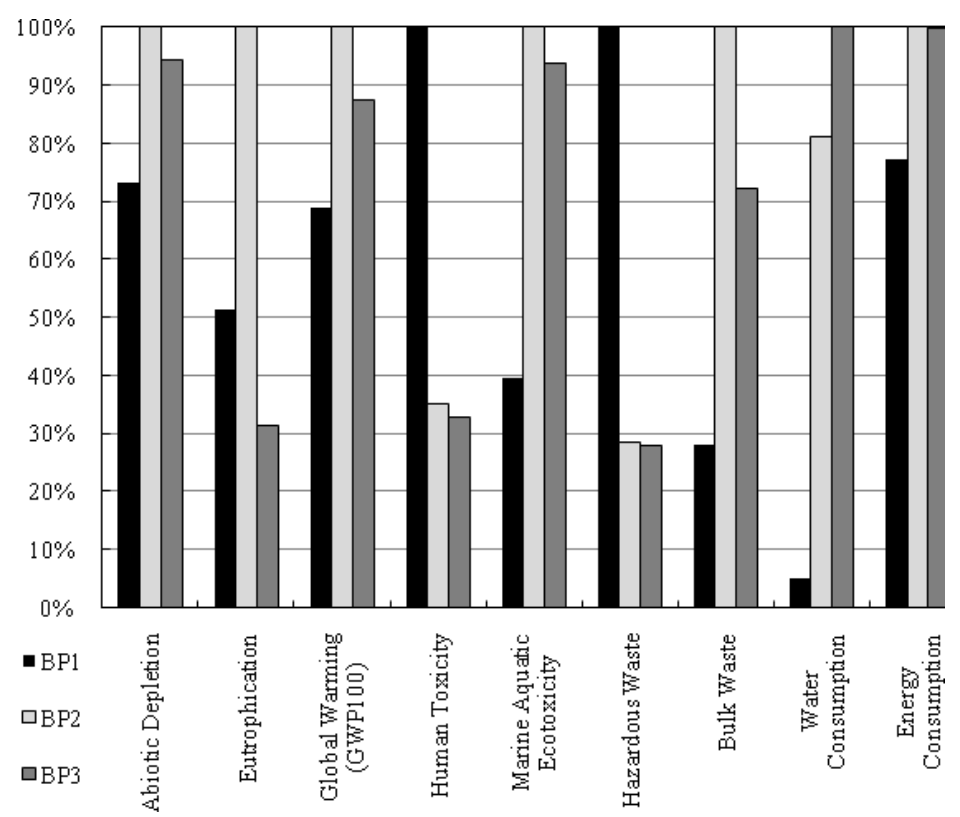

Figure 4 Complete LCA of all 3 backpacks $(\mathrm{BP} 1=$ backpack $1 ; \mathrm{BP} 2=$ backpack $2 ; \mathrm{BP} 3=$ backpack 3 this is common to all proceeding figures).

The complete LCA of all three backpacks are displayed in Figure 4. For organic (BP3) and conventional cotton (BP2), abiotic depletion and global warming is problematic due to the use of fossil fuels in the production of the cotton fabric. The organic cotton backpack 3 does extremely well in the eutrophication indicator due to the absence of fertilisers in the farming of the organic cotton crop. Hazardous waste is significantly reduced, a minimum reduction of $74.4 \%$, and a $65.8 \%$ drop in human toxicity, primarily due to the significantly reduced release of toxic chemicals upon incineration and use of water based paint. Bulk waste is larger for the cotton backpacks 2 and 3 due to the increased mass of waste cotton produced during the fabric manufacturing process and assembly process. Water consumption is extremely high for cotton; particularly organic cotton, requiring a minimum of $81.9 \%$ more water for each backpack produced. Energy consumption is approximately $22.5 \%$ higher for backpacks 2 and 3 due to the processing of cotton fibre into fabric overseas. It is evident here that the new backpacks do not perform as well as backpack 1, being more impactful on all but two indicators, human toxicity and hazardous waste. The poor results of the redesigned backpacks can be attributed to the new cotton fabrics. 


\subsubsection{Environmental impacts of phases of the products.}

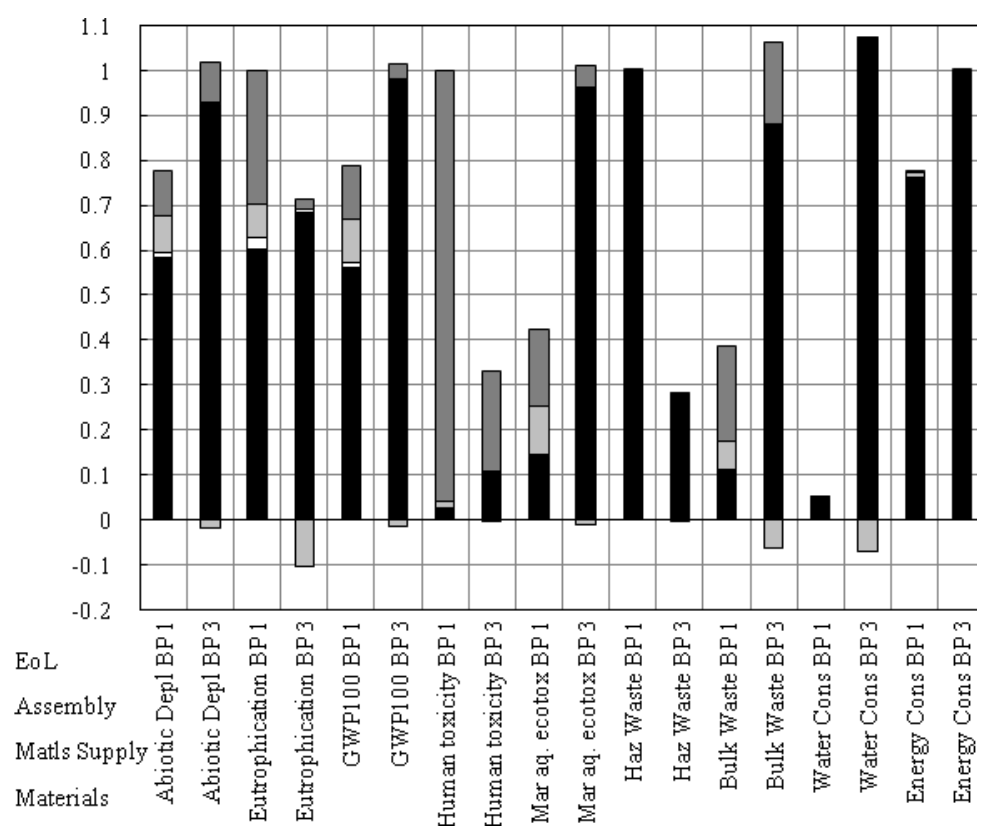

Figure 5 Analysis of 4 product stages (Materials used/Supply of Materials/Assembly/EoL) for Backpack $1 \& 3$.

Figure 5 reveals the analyses of the 4 major product stages (for backpacks 1 and 3): 1) the production of all elements (all elements are imported) used in the final backpack assembly, 2) supply of all elements to production point, 3) the processes used in producing the backpack on island and 4) the end-of-life scenario, also completely constrained to Fiji. Figure 5 shows the contribution of each product stage to the overall backpack life cycles shown in Figure 4. It is clear that for abiotic depletion, eutrophication, global warming potential, hazardous waste, water and energy consumption, the bulk of the impact is generated from material production. Organic cotton production has a detrimental effect primarily due to excessive water consumption during production and the use, by overseas producers, of coal fired power plants in the manufacturing phase of the fabric. The transportation of materials to the point of manufacture is negligible compared to the other product stages. Therefore the supply process is the least impactful stage followed by the end-of-life stage. It is evident from figure 5 that the majority of impact categories are affected by the creation of the backpack materials used in the final assembly. Detailed analysis of this reveals that the organic cotton fabric production is the most environmentally impactful followed by the Cel-Aire ${ }^{\mathrm{TM}}$ polyethylene foam and zip. Due to the recycling on cotton fabric and waste paper, there is some recovery during the assembly stage indicated by the negative contributions. 


\subsubsection{Analysis of Backpack Components}

\section{The Fabric}

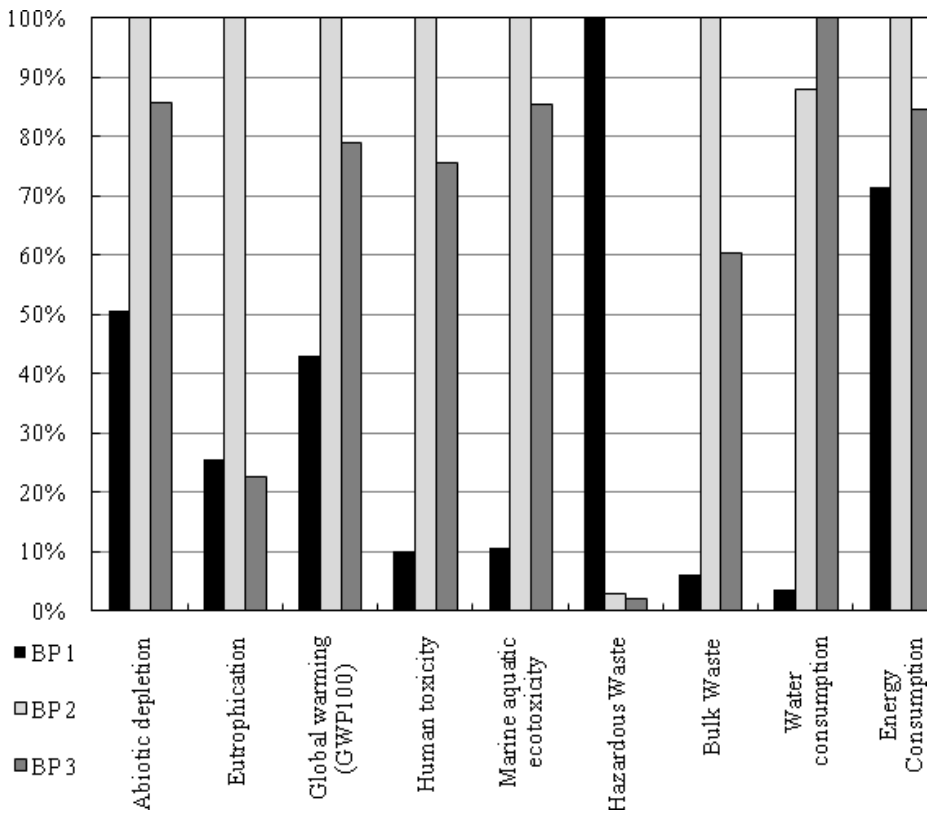

Figure 6. Comparison of Production of organic (BP3), normal (BP2) Cotton vs. Polyester (BP1) for Fabric Only.

Figure 6 shows the results of the LCA conducted on normal cotton fabric used in backpack 2 (produced using conventional methods including the use of fertilisers); organic cotton fabric used in backpack 3 (excluding fertilizers), and polyester fabric used in backpack 1. Hazardous waste is significantly reduced by $97.5 \%$ for cotton and $98.0 \%$ for organic cotton with the introduction of cotton fabrics in the backpack; however due to the production of these cotton fabrics in countries with high reliance on coal fired power generation, principally China, the other indicators show the impact of the harvesting and weaving processes associated with cotton fabric production. Bulk waste at disposal is also increased due to the manufacturing processes applied in the production of the cotton fabric. The energy used to make the cotton fabrics is $29.6 \%$ and $13.2 \%$ higher for organic and normal, respectively, compared to polyester. The water consumption impact category also highlights the copious amount of water required to grow cotton, however, again this impact is felt completely overseas as no cotton is grown in Fiji. Analysis of materials used in the assembly of Backpack 2 and 3 , it was clear that cotton fabric was by far the largest contributor to abiotic depletion, eutrophication, global warming, human toxicity, marine aquatic toxicity, bulk waste, and water consumption, almost entirely restricted to the manufacturing phase of the fabric. The new organic fabric, introduced after the LCA, performs better in all indicators except for water and energy consumption. 


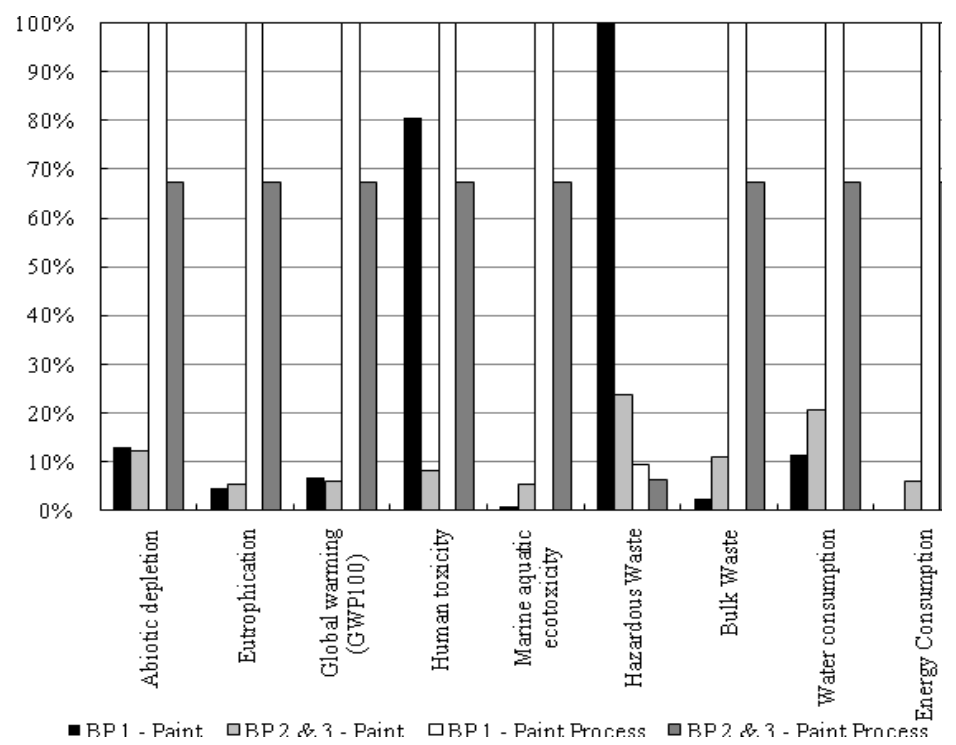

Figure 7. Comparison of Paint and Painting Process.

It should be noted that the paint and painting process for Backpacks 2 and 3 are identical and are thus combined here. When considering the entire painting process and the paint itself shown in Figure 7, it is clear that the baking process has a significantly greater influence on all impact categories (the paint process consists of hand screen printing and an oven cure), except hazardous waste, as compared to the paint. In particular, the decision to switch to water based paint plays a positive role in reducing hazardous waste by $76.1 \%$ and a $72.3 \%$ reduction in human toxicity. The energy reduction policy also plays a significant role in reducing the impact of the paint baking process by $32.8 \%$ on all indicators excluding hazardous waste. It is clear though that the paint is by far the greatest contributor to hazardous waste even more so than electricity production.

\section{Packaging}

As mentioned earlier, the weight of the PE packaging used for the distribution of the backpacks to retailers was decreased by $97.5 \%$. Unfortunately, due to a very low weight of the packaging compared to the backpack weight, the benefits are almost not observable on LCA charts and are thus not presented here. 


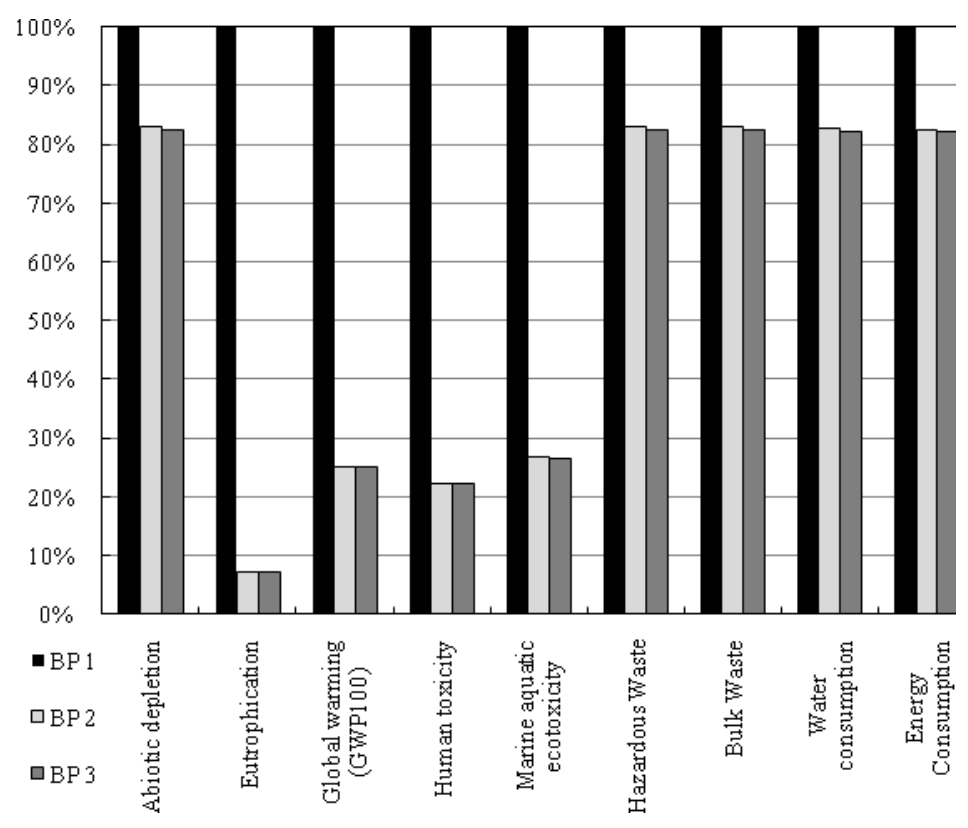

Figure 8 End-of-life Scenario for Cotton and PE Backpacks

Finally, presented in Figure 8 is the analysis of the end-of-life scenarios (presented in Table 3) only. Eutrophication, global warming, human toxicity and marine aquatic toxicity and reduced by a minimum of $73 \%$, whilst the other indicators all show improvements. Abiotic depletion, hazardous and bulk waste, and water consumption are restrained to $83 \%$ of that exhibited by the polyester backpack. The primary reason for these reductions is due to the use of cotton fabric and water based paint in the cotton backpacks where upon incineration the emissions to air and land are reduced and less harmful.

\section{Discussion}

4.1 Benefits of the adapted D4S methodology in Fiji

\subsubsection{Planet benefits}

D4S study represent a qualitative approach to ecodesign which in most instances, particularly for developing economies, is more than sufficient for companies to make environmentally responsible and conscious improvements to their products [18]. Based on the D4S redesign improvement options and presented strategies, the Fiji-based design team developed a sound set of internal and external drivers for product improvement. The D4S method brought about some important shifts in life cycle thinking. Firstly, a renewable and biodegradable material, cotton, was selected to replace what was perceived to be a highly impactful material; polyester. The second iteration of the backpack involved the use of organic cotton fabric. This revision eliminated the use of agro-chemical inputs and limited the impact to the environment and wildlife in the growth phase of the cotton crop. However, due to lower productivity, it also has the added impact of increasing the amount of water consumed compared to normal cotton. Secondly, oil based paint was replaced by a water based paint thereby 
reducing hazardous waste problems, improving employee working conditions, and reducing the impact at the backpack end-of-life. Thirdly, the amount of packaging used for the distribution stage of the product was reduced by $97 \%$, again reducing waste. Since disposal of plastic is a major problem in Fiji, any reduction in volume be it litter (less plastic bags have less chance to be taken by wind), landfill, or incineration is welcomed. Considering that many bags thrown away usually end up in the ocean, causing major problems to marine life, there is major pressure on consumers and retailers in the Pacific to limit the use of plastic bags. Finally, factory-centred improvements such as an energy savings policy, increased paper recycling and safer working conditions were all positive results of this D4S project and impacted positively the product.

\subsubsection{People benefits}

The social benefits of the new bags are experienced on three levels: at the national economy, at the factory and at the retail store. Thanks to the new backpack, the local company should become more profitable, thus contributing to a sustainable the local textile industry, which is of particular social importance in Fiji. Factory based benefits arise through the handling of less harmful paints, thereby improving working conditions and reducing the amount of hazardous waste, and the problems associated with storage, and disposal. The creation of the team within the factory also fostered a more inclusive design process integrating sections within the company thereby promoting life cycle thinking. At the retail store consumers were exposed to a simplified environment product declaration promoting the benefits of the newly ecodesigned backpack. This environmental information was extremely important in educating the consuming public to the environmental issues facing Fiji, and the world. In the future, it could be possible to quantitatively assess these people benefits, using for example the S-LCA guidelines [29].

\subsubsection{Profit benefits}

\section{Cost of the backpack}

The cost of organic cotton was slightly higher due to its relatively limited supply, and in part due to relatively low yields [28]. Costs were saved in the reduction of plastic packaging and also in the reduction in electricity used for assembly. Moreover, none of the new materials required new manufacturing techniques (sewing of cotton fabric, baking process for the new paint) and therefore posed no technical problems or major expenses. The volume of imported materials within Fiji for the backpack assembly did not reduce since in most cases it was a direct substitution and all raw materials are imported. Consequently, no major increase in the backpack price was observed.

\section{A more marketable backpack}

The redesigned backpack was viewed by the company as a major selling point, differentiating their product from those of their competitors. This also provided the company with an avenue to develop a 
Fiji-made environmental product declaration/label that was written by USP and attached to the backpack highlighting the product's environmental performance. The company also viewed the ecodesigned backpack as a new entry into the export market, with growing concern for the environment demonstrated by their customers, allowing them to pitch their product on levels other then price. The new backpack is also more attractive. The cream coloured cotton fabric provides greater flexibility for the application of different colour schemes that was not possible with the black polyester fabric in backpack 1 . As a result, within the first few months of being launched the sales for backpack 3 doubled compared to the polyester variant. Consequently, manufacture of the former version of the bag was discontinued.

\subsection{Applicability of D4S methodology in Fiji}

While European companies are currently enjoying an ecodesign product revolution, it has been exceptionally challenging to find partners for D4S projects within Fiji. The following reasons were observed: 1) companies felt they didn't need to innovate mainly due to the lack of pressure from environmental enforcement bodies or lack of awareness, 2) a vast majority of manufacturers do not design their own products and as such do not have control or authority to redesign; these 'capacity companies' for the most part export to Australia and New Zealand and do so primarily from a price point of view; 3) companies were intimated or associate "environmentally friendly" products with higher product and production costs, 4) companies were suspicious of any outside voluntary assistance and didn't trust that their 'secrets' would remain confidential, 5) companies felt they didn't have the time to entertain the methodology, and 6) it appeared they felt intimidated by the seemingly academic nature of the exercise.

These reasons severely limited our prospects of securing a willing industrial partner for this first adapted D4S project in SIDS and Fiji. This is not such a surprising finding since awareness and enforcement of environmental legislations is limited in the South Pacific region, with few incentives for companies to innovate. Moreover, South Pacific customers are not very demanding on environmental performances of products.

To change this situation, the following two step strategy is currently being proposed by the University of the South Pacific: the D4S project should now focus on products to be exported to demanding markets (Australia, New Zealand, Europe, USA) or on products that can attract environmentally conscious tourists; sectors such as outdoor and beach textiles, and mineral water packed in PET bottles should be targeted first. Benefiting from the results of the first stage, the adapted D4S project should then extend its activity to products highly consumed by Fiji customers, for example local food products.

4.3 Benefits and drawbacks of associating LCA with D4S

\subsubsection{LCA adds value to D4S}


The LCA of the new products shows that care needs to be taken when applying the D4S methodology. Perception of cotton as an environmentally friendly material purely on a qualitative basis does not equate to a quantifiable improvement over the polyester fabric. It underlines again the difficulty of choosing relevant ecodesign strategies (here "Selection of low impact materials - Renewable materials") when the whole life cycle context of a product or a material is not fully understood [30]. This prioritization remains difficult until an LCA (at least simplified LCA) is carried out, or until an ecodesign expert is involved in the D4S project.

\subsubsection{LCA results must be analysed according to Fiji context}

\section{Local and global environmental context}

The results of the LCA study of the three backpacks reveal some important observations about the effectiveness of the D4S methodology in Pacific SIDS. From a local perspective the backpack has improved over its previous form in terms of Fiji's priority areas for sustainable development, namely solid waste management: this was observed for the "bulk waste" (Fiji only) and "hazardous waste" impact categories, as well as the contribution of the end-of-life stage for all impact categories. Globally the redesigned backpacks do not perform as favourably particularly in terms of water and energy consumption, marine aquatic toxicity, abiotic depletion, and bulk waste (globally). Moreover, BP2 and 3 perform poorly against BP1 in terms of Global Warming Potential: however, is this weakness significant when one considers that Pacific SIDS contribute less than $0.06 \%$ to global greenhouse gas emissions but are suffering a disproportionate share of the adverse effects of climate change?

This is where a hierarchy of impacts is important. In relation to production of raw materials, Fiji has little power to affect change in these areas; they can only control material selection and method of transportation to Fiji. Of course Fiji manufacturers should aim minimise the overall impact of the products they make, but a more focused effort must be directed at the assembly and end-of-life stages since these are more impactful on Fiji.

Finally, based on the EVI indicators and priorities identified by the Fiji Ministry of Environment, the assembly and end-of-life scenario for the new backpacks can be considered more environmentally friendly for Fiji than the polyester backpack.

\section{Concentrating on locally relevant ecodesign strategies}

It was demonstrated earlier that the benefits of a key improvement for the backpack (i.e. the reduction of packaging) were too small to be observable in the LCIA charts. A rational implication of this result might be that this improvement should not be a priority of the company. However, in the Fiji context, we argue that such an improvement should be maintained for the following reasons:

1. there is a high societal pressure to reduce the number of plastic bags to prevent impact to marine life; 
2. this action is the only reduction-orientated action (and not substitution): such an approach should be encouraged as it could have some very significant benefits in other products that this and other companies .

4.4 Possible improvements

\subsubsection{For the product}

Based on this LCA study it would seem there are a few modifications that can be made to further reduce the backpacks overall environmental impact. These may include the adoption of a locally produced fabric. Although currently not in production, there are possibilities in Fiji for to move into bamboo, banana and hemp fabric production. This would lessen the impact of fabric production by way of reducing water consumption since Fiji enjoys consistent rainfall and all three floras currently grow naturally in Fiji. Such an initiative would also contribute to job creation in Fiji.

\subsubsection{For the adapted D4S method}

One of the goals outlined in section 2.1 was to ensure that the adapted D4S methodology can be implemented in other products and sectors within Fiji and other SIDS. To improve the chances of companies even considering this project, greater awareness and consultation needs to occur between stakeholders and developers of the D4S methodology. The following suggestions should be considered in future projects:

1. Develop a Pacific D4S committee to validate D4S approach: the Pacific has a unique set of challenges that require a targeted approach. Tailoring the D4S methodology towards Pacific SIDS will serve to enhance accessibility, create an inclusive atmosphere for local stakeholders thereby allowing them to "buy-in" to the D4S method, and increasing awareness of the benefits of the D4S methodology.

2. Develop a UNEP label in consultation with USP and a communication policy (Environmental Product Declaration): If companies can see that they can receive a label identifying compliance and/or environmental product improvements, this may convince them to adopt the methodology. Essentially, strict compliance with the D4S methodology validated by the Pacific D4S Committee will ensure the acquisition of a label.

3. In the long term it would be prudent to develop a LCIA method (toxicity) relevant and simpler for Fiji ecosystems and companies, respectively: as shown in this project, an LCA applied within a European context with associated impact indicators is not necessarily relevant to the SIDS context particularly when entire life cycle systems are not contained on island. In future the framework may be developed to assist in the development of a LCIA method specifically tailored to the SIDS context. Also, in the Pacific today, implementing LCA without formal training seems extremely difficult; therefore simpler tools need to be developed. 


\section{Conclusions}

The first application of the D4S methodology in a SIDS was applied to redesign a backpack manufactured, sold, used and disposed of in Fiji. The qualitative nature of the classical D4S methodology to redesign a backpack produced good results for Fiji in terms of minimising the use of non renewable materials, reducing hazardous waste, minimising energy consumption, and improving working conditions. To quantitatively assess these results, a LCA of the old and new products was conducted. These results differentiate the impact of the product between local and global impact indicators. The LCA highlights the need to consider separately the life cycle stages of the backpack from material production/extraction through to end-of-life. That is, although the backpack performs poorly on a global scale on some environmental aspects, the new backpack is better for the Fiji environment. This new adapted D4S methodology, incorporating LCA, is a useful tool for designers. However, it is suggested that a longer term effort needs to be made to make this adapted D4S method simpler for use in developing countries.

\section{ACKNOWLEDGEMENTS}

This work project was supported by funding from Agence Universitaire de la Francophonie (AUF), French "Fonds Pacifique", and the United Nations Environment Programme (UNEP). The authors would like to thank Mr Colin Philps of Wai Tui, Mr William Lepercq, Mr Pascal Pagand, and Ms Lucie Domingo for their assistance during the project.

\section{REFERENCES}

1. UN, The Johannesburg Declaration on Sustainable Development, United Nations, Editor. 2002: Johannesburg (Republic of South Africa).

2. Nassau Declaration. 2004, Ministerial SIDS Inter-regional Preparatory Meeting: Nassau (Bahamas).

3. Ministry of National Planning, Strategic Development Plan 2007-2011. 2007, Government of Fiji: Suva (Fiji).

4. $\quad$ Fiji Islands Bureau of Statistics, Fiji Facts and Figures as at 1st July 2008. 2008: Suva (Fiji).

5. Burns, T., and Australian Agency for International Development, Management of persistent organic pollutants in Pacific Island countries: waste and obsolete chemicals and chemical contaminated sites. 2000: AusAID.

6. $\quad$ Pratt, C., U. Kaly, and J. Mitchell, Manual: How to Use the Environmental Vulberability Index (EVI). 2004, SOPAC \& UNEP.

7. Briguglio, L., Small Island Developing States and their Economic Vulnerabilities. World Development, 1995. 23(9): p. 1615-1632.

8. Pratt, C., U. Kaly, and J. Mitchell, EVI: Description of Indicators. 2004, SOPAC \& UNEP.

9. Mathieux, F., Kumar, S., Koshy, K., Mataki, M. The value-added of engineering students in the search of adapted solutions to solid waste management in Small Islands Developing States: the example of the Fiji Islands. in International 
Conference on Engineering Education in Sustainable Development (EESD) 2006. 2006. Lyon (France).

10. Kumar, S., Mathieux, F., Onwubolu, G., Chandra, V., A novel powder metallurgybased method for the recycling of aluminum adapted to a small island developing state in the Pacific. International Journal of Environmentally conscious Design and Manufacturing, 2007. 13(3, 4): p. 1-22.

11. Department of Environment, National Solid Waste Managment Strategy \& Action Plans 2008-2010. 2008, Ministry of Tourism and Environment: Suva (Fiji).

12. Ramjeawon, T., A Case Study of Cleaner Production Opportunities in Small and Medium Enterprises on the Island of Mauritius. Electronic Green Journal, 2004. 1(20): p. 1-14.

13. Ramjeawon, T., von Blottnitz, H., Kituyi, E., Mebratu, D., LCA knowledge network in Africa (ALCANET). International Journal of Life Cycle Assessment, 2005. 10(6): p. 449-449.

14. Foolmaun, R.K. and T. Ramjeawon, Life Cycle Assessment (LCA) of PET bottles and comparative LCA of three disposal options in Mauritius. International Journal of Environment and Waste Management, 2008. 2(1/2): p. 125-138.

15. Almeida, C., Rodrigues, A. J. M., Bonilla, S. H., Giannetti, B. F., Emergy as a tool for Ecodesign: evaluating materials selection for beverage packages in Brazil. Journal of Cleaner Production, 2010. 18(1): p. 32-43.

16. Pigosso, D.C.A., et al., Ecodesign methods focused on remanufacturing. Journal of Cleaner Production, 2010. 18(1): p. 21-31.

17. Masera, D., Sustainable product development: a key factor for small enterprise development - the case of furniture production in the Purépecha region, Mexico. The Journal of Sustainable Product Design, 1999(8): p. 28-39.

18. Crul, M., Ecodesign in Central America. 2003, Delft University of Technology: Delft (Netherlands), $\mathrm{PhD}$ Thesis.

19. UNEP and T.U. Delft. Design for Sustainability: A Practical Approach for Developing Economies 2007 [cited 201026 January]; Available from: http://www.d4s-de.org/.

20. Mathieux, F., Evrard, D., Mataki, M., Koshy, K.,. Sustainability and adapted product ecodesign in Small Island Developing States of the South Pacific. in 15th CIRP LCE (life Cycle Engineering) Conference. 2008. Sydeny, Australia.

21. Storey, D., The Fiji Garment Industry. 2004, OXFAM New Zealand.

22. UNEP and T.U. Delft. Design for Sustainability: A Practical Approach for Developing Economies - Worksheets. 20072007 [cited 201026 January]; Available from: http://www.d4s-de.org/.

23. ISO, ISO 14040:2006 Environmental Management - Life Cycle Assessment Principles and Framework. 2006, International Oganization for Standardization.

24. ISO, ISO 14044:2006 Environmental Management - Life Cycle Assessment Requirements and Guidelines. 2006, International Organization for Standardization.

25. Fiji Electricity Authority, FEA Annual Report 2008. 2008, Fiji Electricity Authority Suva (Fiji).

26. Molto, J., Conesa, J. A., Font, R., Martin-Gullon, I., Organic compounds produced during the thermal decomposition of cotton fabrics. Environmental Science \& Technology, 2005. 39(14): p. 5141-5147.

27. Molto, J., Font, R., Conesa, J. A., Study of the organic compounds produced in the pyrolysis and combustion of used polyester fabrics. Energy \& Fuels, 2006. 20(5): p. 1951-1958. 
28. Kooistra, K. and A. Termorshuizen, The Sustainability of Cotton. 2006, Biological Farming Systems, Wageningen University.

29. UNEP, Guidelines for Social Life Cycle Assessment of Products, ed. UNEP. 2009: United Nations Environment Programme.

30. Mathieux, F., Rebitzer,G., Ferrendier,S., Simon,M.,Froelich,D., Ecodesign in the European Electr(on)ics Industry - An analysis of the current practices based on cases studies. Journal of Sustainable Product Design, 2001. 1(4): p. 233-245. 